\begin{tabular}{|c|c|c|}
\hline 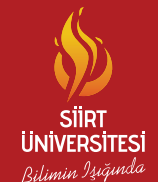 & $\begin{array}{l}\text { Türkiye Tarımsal Araştırmalar Dergisi } \\
\text { dergipark.org.tr/tutad }\end{array}$ & $\begin{array}{l}\text { Turk J Agric Res } \\
\text { 2021, 8(1): 27-33 } \\
\text { ๑) TÜTAD } \\
\text { ISSN: 2148-2306 } \\
\text { e-ISSN: 2528-858X } \\
\text { doi: 10.19159/tutad.785130 }\end{array}$ \\
\hline
\end{tabular}

\title{
Bazı Bitki Ekstraktlarının Botrytis cinerea Persoon ve Sclerotinia sclerotiorum (Libert) de Bary Üzerindeki Etkinliğinin Belirlenmesi
}

\author{
Sevim ATMACA, Şeyda ŞİMŞEK*, Zeliha KAYAASLAN, Gamze PEKBEY \\ Yozgat Bozok Üniversitesi, Ziraat Fakültesi, Bitki Koruma Bölümü, Yozgat, TÜRKIYE
}

\begin{tabular}{l}
\hline Geliş Tarihi/Received: 25.08.2020 Kabul Tarihi/Accepted: 04.02.2021 \\
\hline ORCID ID (Yazar sırasina göre / by author order) \\
$\begin{array}{l}\text { (Dorcid.org/0000-0001-8568-3469 (1Dorcid.org/0000-0002-0096-8949 } \\
\text { "Sorumlu Yazar/Corresponding Author: seyda.simsek@yobu.edu.tr }\end{array}$
\end{tabular}

Öz: Bu çalıșmada, Humulus lupulus L., Bifora radians B. ve Achillea millefolium L.'dan elde edilen metanol ekstraktlarının Botrytis cinerea Persoon ve Sclerotinia sclerotiorum (Libert) de Bary bitki patojenlerine karşı etkinlikleri araştırılmıştır. Denemeler; agar petri yöntemiyle $24 \pm 1{ }^{\circ} \mathrm{C}$ sıcaklıkta, bitki ekstraktlarının \% $0.5, \% 1, \% 2, \% 4, \% 8$ (w/v)'lik dozları kullanılarak yürütülmüştür. Veriler Tukey testi $(\mathrm{p}<0.05)$ ile değerlendirilmiştir. Her bir bitki ekstraktı için maksimum antifungal etki \% 8'lik dozda elde edilmiştir. A. millefolium ve H. lupulus ekstraktları \% 4 ve \% 8'lik dozlarda Botrytis cinerea ve S. sclerotiorum'un miselyum gelişimini \% 100 inhibisyon oranıla önlemiştir. Bifora radians ekstraktı \% 8'lik dozda Botrytis cinerea ve S. sclerotiorum'un gelişimini \% 100 engellemiştir.

Anahtar Kelimeler: Botrytis cinerea, Sclerotinia sclerotiorum, Humulus lupulus, Bifora radians, Achillea millefolium

\section{Determination of the Effectiveness of Some Plant Extracts on Botrytis cinerea Persoon and Sclerotinia sclerotiorum (Libert) de Bary}

\begin{abstract}
This study aimed to investigate the antifungal activities of methanol extracts, against the plant pathogens Botrytis cinerea Persoon and Sclerotinia sclerotiorum (Libert) de Bary, obtained from Humulus lupulus L., Bifora radians B. and Achillea millefolium $\mathrm{L}$. The experiments were carried out by agar plate method at $24 \pm 1{ }^{\circ} \mathrm{C}$ temperature with using $0.5 \%$, $1 \%, 2 \%, 4 \%, 8 \%(\mathrm{w} / \mathrm{v})$ dose of plant extracts. The data were evaluated with Tukey test $(\mathrm{p}<0.05)$. The maximum antifungal effect was observed at $8 \%$ dose for each plant extract. A. millefolium and $H$. lupulus extracts prevented the mycelium growth of Botrytis cinerea and S. sclerotiorum with $100 \%$ inhibition rate at the $4 \%$ and $8 \%$ dose. Bifora radians extract prevented $100 \%$ growth of Botrytis cinerea and S. sclerotiorum at a dose of $8 \%$.
\end{abstract}

Keywords: Botrytis cinerea, Sclerotinia sclerotiorum, Humulus lupulus, Bifora radians, Achillea millefolium

\section{Giriş}

Coğrafik özellikleri bakımından birçok tarım ürününün yetiştirilebilmesine uygun iklim ve toprak özelliklerine sahip olan Türkiye'de; meyve, sebze ve tahıl grubu ürünlerin tarımı yoğun olarak yapılmaktadır. Türkiye ekonomisinde önemli bir yer oluşturan bu ürünler yetiştiriciliği ve depolanması esnasında birçok hastalık etmeni tarafından enfekte olmaktadır. Özellikle hasat sonunda meydana gelen enfeksiyonların çoğuna funguslar neden olmaktadır (Gatto ve ark., 2011).

Fungal patojenler hem açık tarla hem de örtü altı sebze yetiştiriciliğinde önemli verim kayıplarına yol açarlar. Dünya genelinde örtü altı sebze üretiminin yaygın patojenlerinden biri olan Sclerotinia türleri beyaz çürüklük, gövde çürüklüğü veya meyve çürüklüğü olarak adlandırılan hastalıklara neden olmaktadır (Farr ve 
ark., 1989). S. sclerotiorum toprak kökenli bir patojen olup, 400'den fazla bitki türünde enfeksiyona neden olmaktadır (Zhang ve ark., 2016). Konukçu bitkilerin yaprak, çiçek, meyve ve gövdelerini enfekte ederek, vejetasyon döneminde veya hasat sonrası hastalıklara sebep olmaktadır (Clarkson ve ark., 2004; Fernando ve ark., 2004; Smolińska ve Kowalska, 2018).

Yaygın bir diğer hastalık etmeni Botrytis cinerea (gri küf hastalığg1) ise, meyve çürüklüğü, çiçek yanıklığı ve gövde ve dal çürüklüğü gibi simptomlar sergilemektedir (Elad ve ark., 2004). Geniş konukçu dizisine sahip olan bu patojenler örtü altı sebze üretiminde olduğu kadar açık tarla yetiştiriciliğinde de lahana, karnabahar, kabak, havuç, patlıcan, fasulye, marul, biber, patates, kavun, domates gibi çok sayıda bitkide önemli düzeyde zarara neden olabilmektedir.

Fungusların neden olduğu hastalıkları önlemek amacıyla tarım alanlarında yoğun bir şekilde fungisit kullanılmaktadır. Ancak, aşırı ve bilinçsiz fungisit kullanımı doğal rekabeti baskılayarak fungusitlere tolerant irkların gelişmesine neden olmakta; aynı zamanda insan ve çevre sağlığını olumsuz yönde etkilemektedir (Torres ve Capote, 2004; Rivas ve ark., 2005). Bu nedenlerden dolay1 kimyasal pestisitlere alternatif olabilecek çalışmalara gün geçtikçe ihtiyaç daha da artmaktadır (Demirci, 1996; Gerbore ve ark., 2014). Doğal dengeyi bozmayan, insan ve çevreye zararlı etkileri olmayan, kimyasal pestisitlerin aksine çok daha kolay parçalanabilen bitkisel kökenli pestisitler, sentetik pestisitler karşısında önemli bir alternatif olmaktadır. Birçok araştırıcı bu sebeplerden dolayı farklı bitkilerden elde ettiği ekstraktların etkinliğini bitki patojenleri üzerinde test etmiştir (Yanar ve ark., 2011; Sun ve ark., 2017; Wang ve ark., 2017). Yapılan çalışmalarda önemli iki patojen olan $B$. cinerea ve $S$. sclerotiorum'a karşı bitkilerden elde edilen ekstraktların etkinliği in vitro ve in vivo ortamlarda farklı araştırıcılar tarafindan ortaya konulmuştur (Gholamnezhad, 2019; Wang ve ark., 2019; Bairwa ve ark., 2020; Wahab ve ark., 2020).

$\mathrm{Bu}$ çalışmada; Humulus lupulus, Bifora radians. ve Achillea millefolium bitkilerinden elde edilen metanol ekstraktının in vitro koşullarında Botrytis cinerea ve $S$. sclerotiorum üzerindeki antifungal etkisinin araştırılması amaçlanmıştır.

\section{Materyal ve Yöntem}

Araştırmanın materyalini 3 farklı bitki (H. lupulus, Bifora radians, $A$. millefolium) türünden elde edilen ekstraktlar ile Botrytis cinerea ve S. sclerotiorum patojenleri oluşturmaktadır. Çalışmada kullanılan bu bitkiler Tokat ilinden çiçeklenme devresinde toplanmıştır. Çalışmadaki bitkilerin ekstraksiyonda kullanılan kısımları ve toplanma zamanları Tablo 1'de verilmiştir. Toplanan bitki materyalleri doğrudan güneş 1şı̆̆ına maruz kalmayacak şekilde oda sicaklığında kurutulmuştur. Kurutulan bitki materyalleri ögütücü vasıtasıyla ögütülmüş ve cam kavanozlara aktarılarak çalışmada kullanılma zamanına kadar karanlık oda koşullarda muhafaza altına alınmıştır.

\subsection{Bitki ekstraktlarının elde edilmesi}

Çalışmada kullanılan bitkilerin öğütülmüş örneklerinden 100 gram tartılarak erlenmayerlere alınmış ve çözücü olarak $500 \mathrm{ml}$ methanol ilave edilmiştir. Yirmi dört saat süreyle metanol içerisinde bekletilen bitkiler, filtre kâğıdından süzülerek elde edilen süspansiyondaki çözücüler evaporatör ile uçurularak bitkisel ekstraktlar elde edilmiştir (Alkan ve Gökçe, 2012).

\subsection{Bitki patojenlerinin eldesi ve yetiştirilmesi}

Çalışmada kullanılan fungal hastalık etmenleri; Botrytis cinerea (gri küf) ve Sclerotinia sclerotiorum Yozgat Bozok Üniversitesi, Bitki Koruma Bölümü, Fitopatoloji laboratuvarı stok kültüründen temin edilmiştir. Fungus kültürünün yetiştirilmesi, çoğaltılması ve antifungal etkinin saptanmasında Patates Dekstroz Agar (PDA) (Merck, 500 g) besi ortamı kullanılmıștır. PDA besi ortamı her bir steril petriye ( $9 \mathrm{~cm}$ çap) $10 \mathrm{ml}$ dökülmüştür. Sonrasında petriler oda şartlarında bir gece bekletilmiş ve daha önceden temin edilen patojen kültürlerinden $4 \mathrm{~mm}$ çaplı diskler alınarak besi ortamının ortasına ekimi yapılmıştır. Daha sonra $24 \pm 1{ }^{\circ} \mathrm{C}$ ' de inkübasyona bırakılmış ve 7-10 günde gelişen patojenler denemelerde kullanılmıştır.

Tablo 1. Çalışmada kullanılan bitkiler

\begin{tabular}{lllll}
\hline Latince ad1 & Familya ad1 & Türkçe ad1 & Kullanılan bitki kısmı & Toplanma zamanı \\
\hline Humulus lupulus L. & Cannabaceae & Şerbetçi otu & Çiçek & Temmuz-Eylül \\
\hline Bifora radians Bieb. & Apiaceae & Kokarot & $\begin{array}{l}\text { Toprak üstü aksam herba } \\
\text { kısmı }\end{array}$ & Mayıs-Ağustos \\
\hline Achillea millefolium L. & Asteraceae & Civanperçemi & $\begin{array}{l}\text { Toprak üstü aksam herba } \\
\text { kismı }\end{array}$ & Haziran-Eylül \\
\hline
\end{tabular}




\subsection{Ekstraktların antifungal etkilerinin saptanması}

H. lupulus, Bifora radians ve A. millefolium'dan elde edilen metanol ekstraktlarının son konsantrasyonları \% 0.5, \% 1.0, $\% 2.0, \% 4.0$ ve $\% 8.0$ olacak şekilde otoklav edilmeden önce PDA ortamlarına ilave edilerek otoklavda $121{ }^{\circ} \mathrm{C}$ 'de 20 dakika sterilize edilmiștir (Özyiğit ve ark., 2018; Belgüzar ve ark., 2019). Sterilize edilen karışımlardan $10 \mathrm{ml}$ alınarak $9 \mathrm{~cm}$ çaplarındaki her bir steril petriye dökülmüştür. Petriler oda şartlarında bir gece bekletildikten sonra PDA besi yerlerinde geliştirilen patojen kültürlerinden birer disk ekilmiștir. İnokulasyondan sonra petrilerin etrafı parafilm ile kapatılıp, $24 \pm 1{ }^{\circ} \mathrm{C}$ 'de inkübasyona bırakılmıştır. Deneme, 2 tekrarlı 3 tekerrürlü olarak yürütülmüş ve kontrol olarak ekstraktlardan ari PDA kullanılmıştır. Çalışmadan 1 hafta sonra fungus koloni çapının birbirine dik iki yönde ölçülmesi ile koloni çapının ölçümü yapılmıştır (Vio-Michaelis ve ark., 2012).

\subsection{Değerlendirme ve istatistiksel analizler}

Koloni çapının birbirine dik iki yönde ölçülmesi ile ortalama misel uzunluğu belirlenmiştir.

Kontrole göre bitki ekstraktlarının engelleme oranları Eşitlik 1 yardımıyla hesaplanmıştır (Fiori ve ark., 2000).

$$
\mathrm{E}=[(\mathrm{K}-\mathrm{M}) / \mathrm{K}] \times 100
$$

Eşitlikte E, engelleme oranını (\%); K, kontrolde koloni çapını (mm); M, muamelede koloni çapını ( $\mathrm{mm}$ ) ifade etmektedir.

Elde edilen sonuçların istatistiki analizleri SPSS 20.0 programı ile yapılmıştır. Tek yönlü varyans analizi (ANOVA) yapilarak muameleler arasındaki farklılıklar \% 5 önem seviyesinde, Tukey çoklu karşılaştırma testi ile analiz edilmiştir.

\section{Bulgular ve Tartışma}

In vitro koşullarında farklı dozlarda uygulanan Bifora radians, $A$. millefolium ve $H$. lupulus ekstraktlarının Botrytis cinerea ve S. sclerotiorum'un ortalama misel uzunluğu üzerindeki etkileri ve engelleme oranları belirlenmiştir.

Çalışma sonucunda, bütün ekstraktların \% 0.5'lik dozları Botrytis cinerea'nın ortalama misel uzunluğuna düşük etkinlik göstermiştir. Botrytis cinerea'nın ortalama misel uzunluğuna en düşük etkinliği Bifora radians $(6 \mathrm{~mm})$ ekstraktı göstermiş ve misel uzunluğu kontrol $(6 \mathrm{~mm})$ ile aynı bulunmuştur. A. millefolium ve $H$. lupulus ekstraktlarının ise ortalama misel uzunluğuna etkisi sirasiyla $5.70 \mathrm{~mm}$ ve $4.63 \mathrm{~mm}$ olarak hesaplanmıştır. İstatistiki olarak $H$. lupulus ekstraktı hariç diğer ekstraktların etkinliği kontrolle aynı grupta yer almıştır $(\mathrm{p}<0.05)$. Tüm ekstraktlar \% 8'lik dozda Botrytis cinerea'nın misel uzunluğunu olumsuz etkilemiş ve ortalama misel uzunluğu $0 \mathrm{~mm}$ olarak ölçülmüştür. Elde edilen sonuçlar istatistiki olarak incelendiğinde ekstraktların etkinliği birbirleri ile aynı grupta yer alırken, kontrole göre anlamlı derecede $(p<0.05)$ farklılık göstermiştir (Tablo 2).

Tüm ekstraktlar \% 8'lik dozda misel gelişimini $\% 100$ engellemiştir. A. millefolium ve $H$. lupulus ekstraktları \% 4'lük dozda da Botrytis cinerea'nın gelişimini \% 100; Bifora radians ekstraktı ise $\%$ 4'lük dozda Botrytis cinerea'nın gelişimi üzerinde \% 25.82 oranında engellemiştir. En düşük engelleme oranın 1 ise $\% 0.5^{\prime}$ lik dozda sirasıla Bifora radians $\left(\begin{array}{ll}\% & 0\end{array}\right)$ ve A. millefolium ( $\left.\% 5\right)$ ekstraktı göstermiştir (Tablo 3).

H. lupulus ekstraktı Botrytis cinerea'ya karş1 en düşük dozda ( $\%$ 0.5), Bifora radians ve A. millefolium ekstraktlarından daha etkili bulunmuştur. Benzer şekilde in vitro koşullarında yapılan bazı çalışmalarda yine H. lupulus

Tablo 2. Ekstraktların farklı dozlarda Botrytis cinerea'nın ortalama misel uzunluğu (mm) üzerine etkisi*

\begin{tabular}{lccccc}
\hline & $\% 0.5$ & $\% 1.0$ & $\% 2.0$ & $\% 4.0$ & $\% 8.0$ \\
\hline Kontrol & $6.00 \pm 0.00 \mathrm{a}$ & $6.00 \pm 0.00 \mathrm{a}$ & $6.00 \pm 0.00 \mathrm{a}$ & $6.00 \pm 0.00 \mathrm{a}$ & $6.00 \pm 0.00 \mathrm{a}$ \\
Bifora radians & $6.00 \pm 0.00 \mathrm{a}$ & $5.33 \pm 0.32 \mathrm{ab}$ & $5.60 \pm 0.40 \mathrm{a}$ & $3.95 \pm 0.08 \mathrm{~b}$ & $0.00 \pm 0.00 \mathrm{~d}$ \\
Achillea millefolium & $5.70 \pm 0.20 \mathrm{a}$ & $4.63 \pm 0.28 \mathrm{~b}$ & $2.07 \pm 0.22 \mathrm{~d}$ & $0.00 \pm 0.00 \mathrm{~d}$ & $0.00 \pm 0.00 \mathrm{~d}$ \\
Humulus lupulus & $4.63 \pm 0.30 \mathrm{~b}$ & $3.22 \pm 0.14 \mathrm{c}$ & $3.33 \pm 0.59 \mathrm{c}$ & $0.00 \pm 0.00 \mathrm{~d}$ & $0.00 \pm 0.00 \mathrm{~d}$ \\
\hline
\end{tabular}

*: Aynı harfle gösterilen ortalamalar arasındaki farklılık $\mathrm{p}<0.05$ düzeyinde önemli değildir.

Tablo 3. Ekstraktların farklı dozlarda Botrytis cinerea'nın gelişimini engelleme oranları (\%)

\begin{tabular}{lccccc}
\hline & $\% 0.5$ & $\% 1.0$ & $\% 2.0$ & $\% 4.0$ & $\% 8.0$ \\
\hline Kontrol & & & & & \\
Bifora radians & 0.00 & 11.17 & 6.67 & 25.82 & 100.00 \\
Achillea millefolium & 5.00 & 22.83 & 65.50 & 100.00 & 100.00 \\
Humulus lupulus & 22.83 & 46.33 & 44.50 & 100.00 & 100.00 \\
\hline
\end{tabular}

Türkiye Tarımsal Araştırmalar Dergisi - Turkish Journal of Agricultural Research 
ekstraktının birçok bitki patojeni fungusa karş1 yüksek aktivite gösterdiği belirlenmiştir (Yanar ve ark., 2011; Bartmańska ve ark., 2018; Nionelli ve ark., 2018). H. lupulus ekstraktının antifungal etkinliğinin yüksek olmasının sebebinin içeriğinde bulunan fenolik bileşiklerden (luteolin, rutin, ferulic asid, ve catechin) kaynaklandığ belirtilmektedir (Taylor ve ark., 2003; Zanoli ve Zavatti, 2008; Ürgeova ve Polivka, 2009; Bocquet ve ark. 2019; Keskin ve ark., 2019).

S. sclerotiorum'un ortalama misel uzunluğu üzerinde en düşük etkinliği çalışmada kullanılan ekstraktların \% 0.5 dozu göstermiştir. H. lupulus ekstraktının \% 0.5 dozu $\quad$ S. sclerotiorum'un ortalama misel uzunluğu üzerinde $2.45 \mathrm{~mm}$ ile en düşük etkinliği göstermiştir. A. millefolium ve Bifora radians ekstraktlarının etkinliği ise sırasıyla $2.13 \mathrm{~mm}$ ve $1.93 \mathrm{~mm}$ olarak hesaplanmıştır. Sonuçlar istatistiki olarak hesaplandığında tüm ekstraktların etkinliği birbirinden ve kontrolden farklı bulunmuştur $(\mathrm{p}<0.05)$. Tüm ekstraktların $\%$ 8'lik dozu S. sclerotiorum'un ortalama misel uzunluğu üzerinde en yüksek etkinliği göstermiş ve tüm ekstraktlarda ortalama misel uzunluğu 0 $\mathrm{mm}$ olarak hesaplanmıştır. İstatistiki olarak ekstraktların etkinliği birbirleri ile aynı grupta yer alırken, kontrole göre anlamlı derecede $(p<0.05)$ farklılık göstermiştir (Tablo 4).

S. sclerotiorum'un misel gelişimini tüm ekstraktlar \% 8'lik dozda \% 100 engellemiştir. $A$. millefolium ve $H$. lupulus ekstraktları $\%$ 4'lük dozda S. sclerotiorum'un gelişimini \% 100 engellerken, Bifora radians ekstraktı ise \% 4'lük dozda $S$. sclerotiorum 'un gelişimini \% 65.80 oranında engellemiştir. En düşük engelleme oranını $\% \quad 0.5$ dozda \% 59.17 ile $H$. lupulus ekstraktı göstermiştir. A. millefolium ve Bifora radians ekstrakları ise sirasiyla $\% \quad 64.50$ ve \% 67.83 oranında S. sclerotiorum'un misel gelişimini engellemiştir (Tablo 5).
Çalışmada kullanılan ekstrakların Botrytis cinerea ve $S$. sclerotiorum üzerindeki etkinliğinin doz artışına paralel olarak arttığı belirlenmiş ve bu sonucun aynı ekstraktlarla yapılmış önceki çalışmalarla benzerlik gösterdiği belirlenmiştir (Bouchra ve ark., 2003; Boyraz ve Koçak, 2006; Li ve ark., 2017; Y1lar ve ark., 2020).

H. lupulus, Bifora radians ve A. millefolium'dan elde edilen metanol ekstraktlarının \% 8'lik dozu Botrytis cinerea ve S. sclerotiorum 'un gelişimini \% 100 engellemiştir. İn vitro koşullarında farklı bitki ekstraktlarının bitki patojeni funguslar üzerinde \% 100 oranında etki gösterdiği birçok araştırıcı tarafından da ortaya konulmuştur (Deans ve Svoboda, 1990, Boyraz ve Koçak, 2006). Benzer şekilde, Şesan ve ark. (2015), Hyssopus officinalis L., Mentha sp. ve Satureja hortensis L. ektraktlarının Botrytis cinerea'nın gelişimini $\% \quad 100$ engellediğini belirtmişlerdir. Yine, Allium ursinum ekstraktının S. sclerotiorum'un gelişimini in vitro koşullarında \% 100 engellediği belirlenmiştir (Pârvu ve ark., 2011).

Botrytis cinerea ve $S$. sclerotiorum'a karş1 yüksek aktivite gösteren $A$. millefolium ekstraktının farklı bitki fungal hastalıklarına karşı da etkili olduğu bildirilmiştir (Fiori ve ark., 2000; Woods-Panzaru ve ark., 2009; Fierascu ve ark., 2015). Bir diğer çalışmada ise Ghorbany ve Salary (2005), Didymella bryoniae ve Fusarium spp.'a karşı A. millefolium ekstraktının antifungal etkisi olduğunu belirlemişlerdir. A. millefolium içeriğinde yüksek miktarda flavonoid (apigenin, rutin, luteolin) ve fenolkarbonik asit içermektedir (Bimbiraite ve ark., 2008; Trumbeckaite ve ark., 2011). İçeriğindeki bu maddelerden dolayı yüksek antimikrobiyal etkinlik gösterdiği düşünülmektedir (Aljancic ve ark., 1999; Trumbeckaite ve ark., 2011).

Tablo 4. Ekstraktların farklı dozlarda Scelerotinia sclerotiorum'un ortalama misel uzunluğu (mm) üzerine etkisi* $^{*}$

\begin{tabular}{lccccc}
\hline & $\% 0.5$ & $\% 1.0$ & $\% 2.0$ & $\% 4.0$ & $\% 8.0$ \\
\hline Kontrol & $6.00 \pm 0.00 \mathrm{a}$ & $6.00 \pm 0.00 \mathrm{a}$ & $6.00 \pm 0.00 \mathrm{a}$ & $6.00 \pm 0.00 \mathrm{a}$ & $6.00 \pm 0.00 \mathrm{a}$ \\
Bifora radians & $1.93 \pm 0.08 \mathrm{~d}$ & $2.00 \pm 0.03 \mathrm{~d}$ & $2.07 \pm 0.00 \mathrm{~d}$ & $1.00 \pm 0.04 \mathrm{~cd}$ & $0.00 \pm 0.00 \mathrm{~d}$ \\
Achillea millefolium & $2.13 \pm 0.14 \mathrm{bc}$ & $1.57 \pm 0.07 \mathrm{e}$ & $1.33 \pm 0.12 \mathrm{e}$ & $0.00 \pm 0.00 \mathrm{~d}$ & $0.00 \pm 0.00 \mathrm{~d}$ \\
Humulus lupulus & $2.45 \pm 0.13 \mathrm{~b}$ & $2.33 \pm 0.06 \mathrm{~b}$ & $1.90 \pm 0.16 \mathrm{~d}$ & $0.00 \pm 0.00 \mathrm{~d}$ & $0.00 \pm 0.00 \mathrm{~d}$ \\
\hline
\end{tabular}

*: Aynı harfle gösterilen ortalamalar arasındaki farklılık $\mathrm{p}<0.05$ düzeyinde önemli değildir.

Tablo 5. Ekstraktların farklı dozlarda Scelerotinia sclerotiorum'un gelişimini engelleme oranları (\%)

\begin{tabular}{lccccc}
\hline & $\% 0.5$ & $\% 1.0$ & $\% 2.0$ & $\% 4.0$ & $\% 8.0$ \\
\hline Kontrol & & & & & \\
Bifora radians & 67.83 & 66.67 & 65.50 & 65.80 & 100.00 \\
Achillea millefolium & 64.50 & 73.83 & 77.83 & 100.00 & 100.00 \\
Humulus lupulus & 59.17 & 61.17 & 68.33 & 100.00 & 100.00 \\
\hline
\end{tabular}


Mevcut literatürde Bifora radians ekstraktının antifungal aktivitesini inceleyen başka bir çalışmaya rastlanmamıştır. Ancak farklı patojenlere karşı etkinliğini inceleyen bazı çalışmalar mevcuttur (Baytop, 1999; Özçelik ve ark., 2004). Köroğlu ve ark. (2012), Bifora radians'ın metanol ekstraktının içeriğinde \% 49 oranında fenolik bileşik barındırdığını belirtmişlerdir. Benzer şekilde çalışmada kullanılan Bifora radians metanol ekstraktının $\%$ 8'lik dozunun Botrytis cinerea ve S. sclerotiorum 'un gelişimini \% 100 oranında engellemesinin bitkinin yüksek fenolik bileşik içeriğinden kaynaklandığı düşünülmektedir.

\section{Sonuçlar}

Yapılan çalışma ile A. millefolium ve $H$. lupulus methanol ekstraktının Botrytis cinerea ve S. sclerotiorum üzerinde $\% 4$ ve $\% 8$ 'lik dozlarda, Bifora radians extraktının da \% 8'lik dozda in vitro koşullarında önemli derecede antifungal etkinlik gösterdiği belirlenmiştir. $\mathrm{Bu}$ sonucun ileride yapılacak diğer çalışmalara katkı sağlayacağı ve tarla denemeleriyle birlikte bu patojenlerle mücadelede iyi bir alternatif olarak değerlendirilebileceği düşünülmektedir.

\section{Teşekkür}

Bu çalışma, “6602B-ZF/17-100” numaralı proje ile Bozok Üniversitesi Proje Koordinasyon Uygulama ve Araştırma Merkezi birimi tarafından desteklenmiştir.

\section{Kaynaklar}

Aljancic, I., Vajs, V., Menkovic, N., Karadzic, I., Juranic, N., Milosavljevic, S., 1999. Flavones and sesquiterpene lactones from Achillea atrata subsp. ultifida: Antimicrobial activity. Journal of Natural Products, 62(6): 909-911.

Alkan, M., Gökçe, A., 2012. Tanacetum abrotanifolium (L.) Druce (Asteraceae)'un gövde ve çiçek ekstraktlarının Sitophilus granarius ve Sitophilus oryzae (Col., Curculionidae)'ye olan kontakt ve davranışsal etkileri. Turkish Journal of Entomology, 36(3): 377-389.

Bairwa, V.K., Godika, S., Sharma, J., Nayak, R.K., Gahlot, N., Choudhary, S., 2020. Management of Sclerotinia rot disease of brinjal (Sclerotinia sclerotiorum Lib.) through indigenous materials under in vitro and in vivo conditions. International Journal of Chemical Studies, 8(4): 881-885.

Bartmańska, A., Wałecka-Zacharska, E., Tronina, T., Popłoński, J., Sordon, S., Brzezowska, E., Bania, J., Huszcza, E., 2018. Antimicrobial properties of spent hops extracts, flavonoids isolated therefrom, and their derivatives. Molecules, 23(8): 2059.
Baytop, T., 1999. Therapy with Medicinal Plants in Turkey (Past and Present). Nobel Medical Publishers, İstanbul.

Belgüzar, S., Yanar, Y., Çetin, M., Özyiğit, Ç., 2019. Bazı bitki ekstraktlarının Clavibacter michiganensis subsp. michiganensis ve Pseudomonas syringae pv. tomato üzerine antibakteriyel etkisinin belirlenmesi. Turkish Journal of Weed Science, 22(2): 203-209.

Bimbiraite, K., Ragazinskiene, O., Maruska, A., Kornysova, O., 2008. Comparison of the chemical composition of four yarrow (Achillea millefolium L.) morphotypes. Biologija, 54(3): 208-212.

Bocquet, L., Sahpaz, S., Bonneau, N., Beaufay, C., Mahieux, S., Samaillie, J., Roumy, V., Jacquin, J., Bordage, S., Hennebelle, T., Chai, F., QuetinLeclercq, J., Neut, C., Riviere, C., 2019. Phenolic compounds from Humulus lupulus as natural antimicrobial products: new weapons in the fight against methicillin resistant Staphylococcus aureus, Leishmania mexicana and Trypanosoma brucei strains. Molecules, 24(6): 1024.

Bouchra, C., Achouri, M., Idrissi Hassani, L.M., Hmamouchi, M., 2003. Chemical composition and antifungal activity of essential oils of seven Moroccan Labiatae against Botrytis cinerea Pers: Fr. Journal of Ethnopharmacology, 89(1): 165-169.

Boyraz, N., Koçak, R., 2006. Bazı bitki ekstraktlarının in vitro antifungal etkileri. Selçuk Üniversitesi Ziraat Fakültesi Dergisi, 20(38): 82-87.

Clarkson, J.P., Phelps, K., Whipps, J.M., Young, C.S., Smith, J.A., Watling, M., 2004. Forecasting Sclerotinia disease on lettuce: toward developing a prediction model for carpogenic germination of sclerotia. Phytopathology, 94(3): 268-279.

Deans, S.G., Svoboda, K.P., 1990. The antimicrobial properties of marjoram (Origanum majorana L.) volatile oil. Flavour and Fragrance Journal, 5(3): 187-190.

Demirci, E., 1996. Fungisitlere karş1 dayanıklılığın gelişimi ve yönetimi. Atatürk Üniversitesi Ziraat Fakültesi Dergisi, 27(4): 576-588.

Elad, Y., Williamson, B., Tudzynski, P., Delen, N., 2004. Botrytis: Biology, pathology and control. In: Y. Elad (Ed.), Botrytis spp. and Systems-an Introduction, Kluwer Academic Publisher, Netherland, pp. 1-6.

Farr, D.F., Bills, G.F., Chamuris, G.P., Rossman, A.Y., 1989. Fungi on Plants and Plant Products in the United States. APS Press, USA.

Fernando, W.G.D., Nakkeeran, S., Zhang, Y., 2004. Ecofriendly methods in combating Sclerotinia sclerotiorum (Lib.) de Bary. Recent Research Developments in Environmental Biology, 1: 329347.

Fierascu, I., Ungureanu, C., Avramescu, S.M., Fierascu, R.C., Ortan, A., Soare, L.C., Paunescu, A., 2015. In vitro antioxidant and antifungal properties of Achillea millefolium L. Romanian Biotechnological Letters, 20(4): 10626-10636. 
Fiori, A.C.G., Schwan-Estrada, K.R.F., Stangarlin, J.R., Vida, J.B., Scapim, C.A., Cruz, M.E.S., Pascholati, S.F., 2000. Antifungal activity of leaf extracts and essential oils of some medicinal plants against Didymella bryoniae. Journal of Phytopathology, 148(7-8): 483-487.

Gatto, M.A., Ippolito, A., Linsalata, V., Cascarano, N.A., Nigro, F., Vanadia, S., Di Venere, D., 2011. Activity of extracts from wild edible herbs against postharvest fungal diseases of fruit and vegetables. Postharvest Biology and Technology, 61(1): 72-82.

Gerbore, J., Benhamou, N, Vallance, J., Floch, G.L., Grizard, D., Regnault-Roger, C., Rey, P., 2014. Biological control of plant pathogens: advantages and limitations seen through the case study of Pythium oligandrum. Environmental Science and Pollution Research, 21: 4847-4860.

Ghorbany, M., Salary, M., 2005. Application of plant products to control some soilborn fungal pathogens. Proceendings of the Fourth World Congress on Allelopathy, August 21-26, Centre for Rural Social Research, Australia, pp. 596.

Gholamnezhad, J., 2019. Effect of plant extracts on activity of some defense enzymes of apple fruit in interaction with Botrytis cinerea. Journal of Integrative Agriculture, 18(1): 115-123.

Keskin, Ş., Şirin, Y., Çakir, H.E., Keskin, M., 2019. An investigation of Humulus lupulus L.: Phenolic composition, antioxidantcapacity and inhibition properties of clinically important enzymes. South African Journal of Botany, 120: 170-174.

Köroğlu, A., Hürkul, M.M., Özbay, Ö., 2012. Antioxidant capacity and total phenol contents of Bifora radians Bieb. FABAD Journal of Pharmaceutical Sciences, 37(3): 123-127.

Li, Y., Shao X., Y., Xu, J., Wei, Y., Xu, F., Wang, H., 2017. Tea tree oil exhibits antifungal activity against Botrytis cinerea by affecting mitochondria. Food Chemistry, 234(1): 62-67.

Nionelli, L., Pontonio, E., Gobbetti, M., Rizzello, C.G., 2018. Use of hop extract as antifungal ingredient for bread making and selection of autochthonous resistant starters for sourdough fermentation. International Journal of Food Microbiology, 266 : 173-182.

Özçelik, B., Kusmenoğlu, S., Turkoz, S., Abbasoğlu, U., 2004. Antimicrobial activities of plants from the Apicaceae. Pharmaceutical Biology, 42(7): 526528.

Özyiğit, Ç., Yanar, Y., Yanar, D., Onaran, A., 2018. Ayvada kahverengi çürüklük (Monilinia fructigena Honey in Whetzel) hastalığının propolis etanol ekstrakt1 ile kontrolü. Gaziosmanpaşa Üniversitesi Ziraat Fakültesi Dergisi, 35(Ek Say1): 108-113.

Pârvu, M., Pârvu, A.E, Vlase, L., Roșca-Casian, O., Pârvu, O., 2011. Antifungal properties of Allium ursinum L. ethanol extract. Journal of Medicinal Plants Research, 5(10): 2041-2046.

Rivas, Z., Márquez, R., Troncone, F., Sánchez, J., Colina, M., Hernández, P., 2005. Contribución de principales ríos tributarios a la contaminación y eutrofización Del Lago de Maracaibo. Ciencia, 13: 68-77.

Smolińska, U., Kowalska, B., 2018. Biological control of the soil-borne fungal pathogen Sclerotinia sclerotiorum-a review. Journal of Plant Pathology, 100: 1-12.

Sun, Y., Wang, Y., Xie, Z., Guo, E., Han, L., Zhang, X., Feng, J., 2017. Activity and biochemical characteristics of plant extract cuminic acidagainst Sclerotinia sclerotiorum. Crop Protection, 101: 7683.

Şesan, T.E., Enache, E., Iacomi, B.M., Oprea, M., Oancea, F., Iacomi, C., 2015. Antifungal activity of some plant extract against Botrytis cinerea Pers. in the blackcurrant crop (Ribes nigrum L.). Acta Scientiarum Polonorum, 14(1): 29-43.

Taylor, A.W., Barofsky, E., Kennedy, J.A., Deinzer, M.L., 2003. Hop (Humulus lupulus) proanthocyanidins characterized by mass spectrometry, acid catalysis, and gel permeation chromatography. Journal of Agricultural Food Chemistry, 51(14): 4101-4110.

Trumbeckaite, S., Benetis, R., Bumblauskiene, L., Burdulis, D., Janulis, V., Toleikis, A., Viskelis, P. Jakstas, V., 2011. Achillea millefolium L. s.l. herb extract: Antioxidant activity and effect on the rat heart mitochondrial functions. Food Chemistry, 12(4): 1540-1548.

Torres, D., Capote, T., 2004. Agroquímicos un problema ambiental global: uso del análisis químico como herramienta para el monitoreo ambiental. Ecosistemas, 13(3): 2-6.

Ürgeova, E., Polivka, L., 2009. Secondary metabolites with antibacterial effects from leaves of different hop cultivars during vegetal periods. Nova Biotechnologica, 9(3): 327-332.

Vio-Michaelis, S., Apablaza-Hidalgo, G., Gómez, M., Peña-Vera, R., Montenegro, G., 2012. Antifungal activity of three Chilean plant extracts on Botrytis cinerea. Botanical Sciences, 90(2): 179-183.

Wahab, M.H.A., Malek, A., Ghobara, M., 2020. Efects of some plant extracts, bioagents, and organic compounds on Botrytis and Sclerotinia Molds. Acta Agrobotanica, 73(2): 1-11.

Wang, Y., Sun, Y., Wang, J., Zhou, M., Wang, M., Feng, J., 2019. Antifungal activity and action mechanism of the natural product cinnamic acid against Sclerotinia sclerotiorum. Plant Disease, 103(5): 944-950.

Wang, Y., Sun, Y., Zhang, X., 2017. Sensitivity and biochemical characteristics of Sclerotinia sclerotiorum to propamidine. Pesticide Biochemistry and Physiology, 135: 82-88.

Woods-Panzaru, S., Nelson, D., McCollum, G., Ballard, L.M., Millar, B.C., Maeda, Y., Goldsmith, C.E., Rooney, P.J., Loughrey, A., Rao, J.R., Moore, E.M., 2009. An examination of antibacterial and antifungal properties of constituents described in traditional Ulster cures and remedies. The Ulster Medical Journal, 78(1): 13-15. 
Yanar, Y., Gökçe, A., Kadıoglu, İ., Çam, H., Whalon, M., 2011. In vitro antifungal evaluation of various plant extracts against early blight disease (Alternaria solani) of potato. African Journal of Biotechnology, 10(42): 8291-8295.

Y1lar, M., Bayar, Y., Onaran, A., 2020. Bazı bitki patojeni funguslara karş1 Humulus lupulus L. bitki ekstraktının antifungal aktivitesi. Bahçe, 49(Özel Say1 1): 113-118.
Zanoli, P., Zavatti, M., 2008. Pharmacognostic and pharmacological profile of Humulus lupulus L. Journal of Ethnopharmacology, 116(3): 383-396.

Zhang, F., Ge, H., Zhang, F., Guo, N., Wang, Y., Chen, L., Ji, X., Li, C., 2016. Biocontrol potential of Trichoderma harzianum isolate T-aloe against Sclerotinia sclerotiorum in soybean. Plant Physiology and Biochemistry, 100: 64-74. 